\title{
Effect of high-flow nasal therapy on dyspnea, comfort, and respiratory rate
}

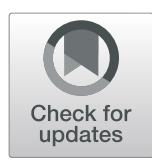

\author{
Andrea Cortegiani ${ }^{1 *} \mathbb{D}$, Claudia Crimi ${ }^{2}$, Alberto Noto ${ }^{3}$, Yigal Helviz ${ }^{4}$, Antonino Giarratano ${ }^{1}$, Cesare Gregoretti ${ }^{1}$ and \\ Sharon Einav ${ }^{4}$
}

\section{Letter to the Editor}

Systematic reviews comparing the effect of high-flow nasal treatment (HFNT) to conventional oxygen therapy (COT) or noninvasive ventilation (NIV) have focused on major clinical outcomes (i.e., endotracheal intubation, mortality) [1-3]. None have explored weaker outcomes that may nonetheless be important from the patient's perspective, yet physiopathological mechanisms suggest that the HFNT may provide some advantage in this regard $[4,5]$. We therefore systematically reviewed all randomized (RCTs) and crossover trials enrolling patients either post-extubation or during acute respiratory failure (ARF), comparing HFNT to COT or NIV and reporting data about dyspnea, comfort, and respiratory rate (RR) (PROSPERO CRD42019119536).

Full search strategy, detailed study methods, reference lists, and risk of bias assessments are reported in Additional file 1.

Twenty-four relevant studies were identified and included: for patients post-extubation, ten RCTs and one crossover trial and, for patients in ARF, eight RCTs and five crossover trials.

The summary of our findings is presented in the Table 1. More studies compared the effects of HNFT vs COT rather than vs NIV. Overall, there seems to be a trend showing that HFNT is probably not inferior to COT in most studies and perhaps better than NIV in terms of dyspnea, comfort, and decreasing of $R R$ in some studies.

Heterogeneity in case-mix, the tools used for outcome assessment and measurement time-points precluded performance of meta-analysis. Neither patients nor treating clinicians were blinded to the intervention in any of the trials, introducing a high risk of detection bias. Differences in HFNT settings (i.e., flow and temperature) and a lack of full description for weaning criteria or protocol may have also contributed to the diversity in findings with regard to comfort and dyspnea.

In this analysis of the literature, the use of HFNT during ARF or post-extubation seems to be not clearly associated with improvements in comfort, dyspnea, and RR since findings from the most recent available evidence were inconsistent. However, in this regard, HFNT does not seem inferior to either COT or NIV. Future research should be focused in assessing patient-reported outcomes using appropriate standardized and validated measures in order to investigate the comparative effectiveness of the different respiratory support strategies.

\footnotetext{
* Correspondence: cortegiania@gmail.com

${ }^{1}$ Department of Surgical, Oncological and Oral Science (Di.Chir.On.S.), Section

of Anesthesia, Analgesia, Intensive Care and Emergency, Policlinico Paolo

Giaccone, University of Palermo, Via del vespro 129, 90127 Palermo, Italy

Full list of author information is available at the end of the article
}

(c) The Author(s). 2019 Open Access This article is distributed under the terms of the Creative Commons Attribution 4.0 International License (http://creativecommons.org/licenses/by/4.0/), which permits unrestricted use, distribution, and

reproduction in any medium, provided you give appropriate credit to the original author(s) and the source, provide a link to the Creative Commons license, and indicate if changes were made. The Creative Commons Public Domain Dedication waiver (http://creativecommons.org/publicdomain/zero/1.0/) applies to the data made available in this article, unless otherwise stated. 


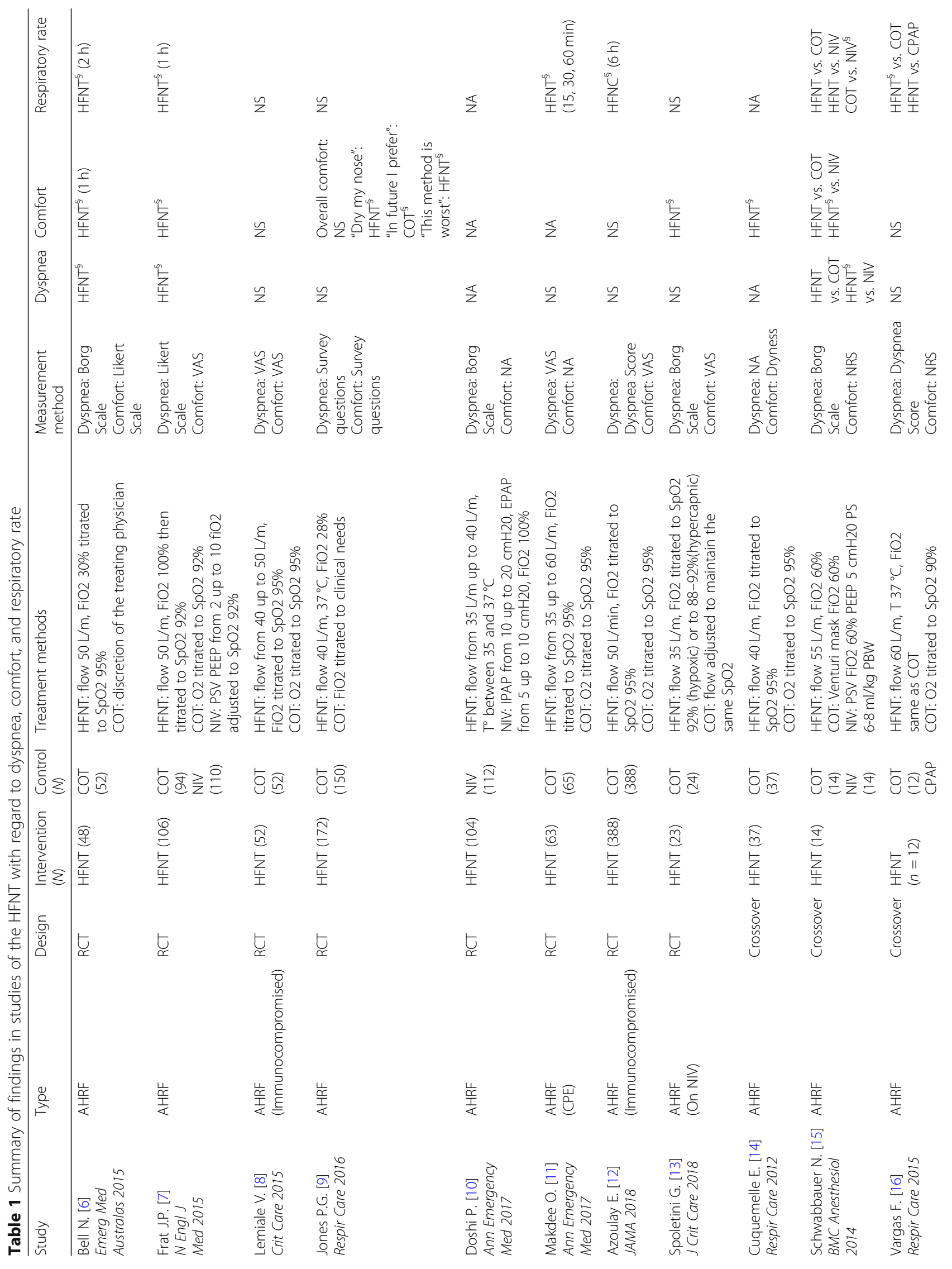




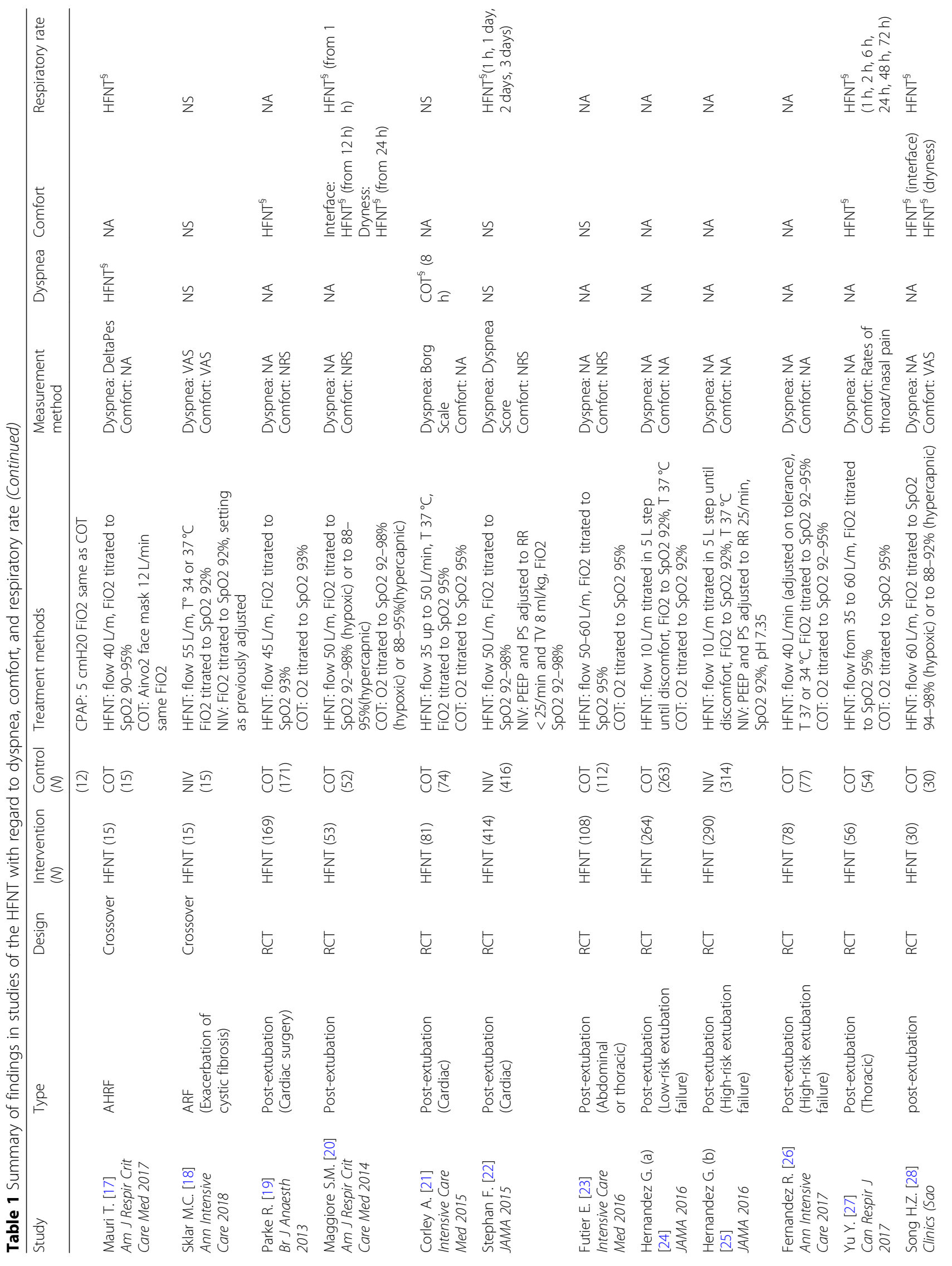




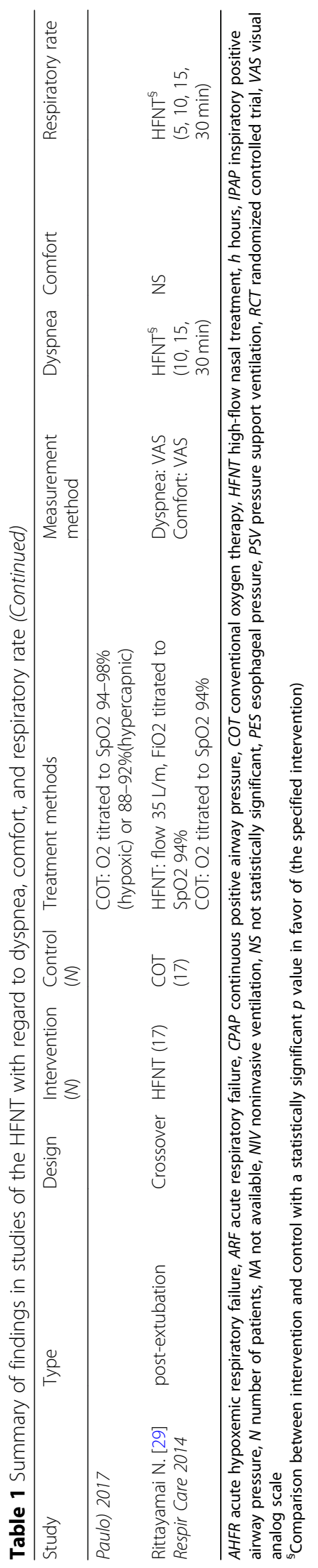




\section{Additional file}

Additional file 1: List of included studies, search strategy, and risk of bias assessment. Detailed study methods, reference list of included studies, search strategy, risk of bias assessment. (DOCX 520 kb)

\section{Abbreviations}

ARF: Acute respiratory failure; COT: Conventional oxygen therapy HFNT: High-flow nasal therapy; NIV: Noninvasive ventilation; $\mathrm{RCT}$ : Randomized controlled trial; RR: Respiratory rate

\section{Acknowledgements}

We would like to thank Dr. Filippo Sanfilippo for his help in registering the manuscript to PROSPERO.

\section{Funding}

None.

\section{Availability of data and materials}

All data generated or analyzed during this study are included in this published article [and its supplementary information files].

\section{Authors' contributions}

$A C, C C, A N, Y E, A G, C G$, and ES contributed substantially to the conception and design of the study, the acquisition of data, or the analysis and interpretation of the data. AC, CC, AN, YE, AG, CG, and ES drafted or provided critical revision of the article and approved the final version of the manuscript.

\section{Ethics approval and consent to participate}

Not applicable.

\section{Consent for publication}

Not applicable.

\section{Competing interests}

Cesare Gregoretti received fees for consultancies or lectures from Orion Pharma, ResMed, Medtronic, Philips, Air Liquide and EOVE, and travel cost reimbursement from Fisher \& Paykel. All other authors declared that they have no competing interests.

\section{Publisher's Note}

Springer Nature remains neutral with regard to jurisdictional claims in published maps and institutional affiliations.

\section{Author details}

${ }^{1}$ Department of Surgical, Oncological and Oral Science (Di.Chir.On.S.), Section of Anesthesia, Analgesia, Intensive Care and Emergency, Policlinico Paolo Giaccone, University of Palermo, Via del vespro 129, 90127 Palermo, Italy. ${ }^{2}$ Respiratory Medicine Unit, A.O.U. "Policlinico-Vittorio Emanuele", Department of Clinical and Experimental Medicine, University of Catania, Via Santa Sofia 78, 95123 Catania, Italy. ${ }^{3}$ Department of Anesthesia and Critical Care, A.O.U. Policlinico "G. Martino", University of Messina, Via Consolare Valeria 1, 98100 Messina, Italy. ${ }^{4}$ Intensive Care Unit of the Shaare Zedek Medical Medical Centre and Hebrew University Faculty of Medicine, Jerusalem, Israel.

\section{Received: 23 April 2019 Accepted: 13 May 2019}

\section{Published online: 05 June 2019}

\section{References}

1. Helviz Y, Einav S. A systematic review of the high-flow nasal cannula for adult patients. Crit Care. 2018;22:71.

2. Cortegiani A, Crimi C, Sanfilippo F, Noto A, Di Falco D, Grasselli G, Gregoretti C, Giarratano A. High flow nasal therapy in immunocompromised patients with acute respiratory failure: a systematic review and meta-analysis. J Crit Care. 2019:50:250-6.

3. Rochwerg B, Granton D, Wang DX, Helviz Y, Einav S, Frat JP, MekontsoDessap A, Schreiber A, Azoulay E, Mercat A, Demoule A, Lemiale V, Pesenti A, Riviello ED, Mauri T, Mancebo J, Brochard L, Burns K. High flow nasal cannula compared with conventional oxygen therapy for acute hypoxemic respiratory failure: a systematic review and meta-analysis. Intensive Care Med. 2019. https://doi.org/10.1007/s00134-019-05590-5.

4. Spoletini G, Cortegiani A, Gregoretti C. Physiopathological rationale of using high-flow nasal therapy in the acute and chronic setting: a narrative review. Trends Anaesth Crit Care. 2019. https://doi.org/10.1016/j.tacc.2019.02.001.

5. Cortegiani A, Accurso G, Mercadante $S$, et al. High flow nasal therapy in perioperative medicine: from operating room to general ward. BMC Anesthesiol. 2018;18:166.

6. Bell N, Hutchinson CL, Green TC, Rogan E, Bein KJ, Dinh MM. Randomised control trial of humidified high flow nasal cannulae versus standard oxygen in the emergency department. Emerg Med Australas. 2015;27:537-41.

7. Frat JP, Thille AW, Mercat A, Girault C, Ragot S, Perbet S, Prat G, Boulain T, Morawiec E, Cottereau A, Devaquet J, Nseir S, Razazi K, Mira JP, Argaud L, Chakarian JC, Ricard JD, Wittebole X, Chevalier S, Herbland A, Fartoukh M, Constantin JM, Tonnelier JM, Pierrot M, Mathonnet A, Beduneau G, Deletage-Metreau C, Richard JC, Brochard L, Robert R, Group FS, Network R. High-flow oxygen through nasal cannula in acute hypoxemic respiratory failure. N Engl J Med. 2015:372:2185-96.

8. Lemiale V, Mokart D, Mayaux J, Lambert J, Rabbat A, Demoule A, Azoulay E. The effects of a 2-h trial of high-flow oxygen by nasal cannula versus Venturi mask in immunocompromised patients with hypoxemic acute respiratory failure: a multicenter randomized trial. Crit Care. 2015;19:380.

9. Jones PG, Kamona S, Doran O, Sawtell F, Wilsher M. Randomized Controlled Trial of Humidified High-Flow Nasal Oxygen for Acute Respiratory Distress in the Emergency Department: The HOT-ER Study. Respir Care. 2016;61:291-9.

10. Doshi P, Whittle JS, Bublewicz M, Kearney J, Ashe T, Graham R, Salazar S, Ellis TW Jr, Maynard D, Dennis R, Tillotson A, Hill M, Granado M, Gordon N, Dunlap C, Spivey S, Miller TL. High-Velocity Nasal Insufflation in the Treatment of Respiratory Failure: A Randomized Clinical Trial. Ann Emerg Med. 2018;72(73-83):e75

11. Makdee O, Monsomboon A, Surabenjawong U, Praphruetkit N, Chaisirin W, Chakorn T, Permpikul C, Thiravit P, Nakornchai T. High-Flow Nasal Cannula Versus Conventional Oxygen Therapy in Emergency Department Patients With Cardiogenic Pulmonary Edema: A Randomized Controlled Trial. Ann Emerg Med. 2017:70:465-472 e462.

12. Azoulay E, Lemiale V, Mokart D, Nseir S, Argaud L, Pene F, Kontar L, Bruneel F, Klouche K, Barbier F, Reignier J, Berrahil-Meksen L, Louis G, Constantin JM, Mayaux J, Wallet F, Kouatchet A, Peigne V, Theodose I, Perez P, Girault C, Jaber S, Oziel J, Nyunga M, Terzi N, Bouadma L, Lebert C, Lautrette A, Bige N, Raphalen JH, Papazian L, Darmon M, Chevret S, Demoule A. Effect of High-Flow Nasal Oxygen vs Standard Oxygen on 28-Day Mortality in Immunocompromised Patients With Acute Respiratory Failure: The HIGH Randomized Clinical Trial. JAMA. 2018;320:2099-107.

13. Spoletini G, Mega C, Pisani L, Alotaibi M, Khoja A, Price LL, Blasi F, Nava S, Hill NS. High-flow nasal therapy vs standard oxygen during breaks off noninvasive ventilation for acute respiratory failure: A pilot randomized controlled trial. J Crit Care. 2018;48:418-25.

14. Cuquemelle E, Pham T, Papon JF, Louis B, Danin PE, Brochard L. Heated and humidified high-flow oxygen therapy reduces discomfort during hypoxemic respiratory failure. Respir Care. 2012:57:1571-7.

15. Schwabbauer N, Berg B, Blumenstock G, Haap M, Hetzel J, Riessen R. Nasal high-flow oxygen therapy in patients with hypoxic respiratory failure: effect on functional and subjective respiratory parameters compared to conventional oxygen therapy and non-invasive ventilation (NIV). BMC Anesthesiol. 2014:14:66.

16. Vargas F, Saint-Leger M, Boyer A, Bui NH, Hilbert G. Physiologic Effects of High-Flow Nasal Cannula Oxygen in Critical Care Subjects. Respir Care. 2015; 60:1369-76

17. Mauri T, Turrini C, Eronia N, Grasselli G, Volta CA, Bellani G, Pesenti A Physiologic Effects of High-Flow Nasal Cannula in Acute Hypoxemic Respiratory Failure. Am J Respir Crit Care Med. 2017:195:1207-15.

18. Sklar MC, Dres M, Rittayamai N, West B, Grieco DL, Telias I, Junhasavasdikul D, Rauseo M, Pham T, Madotto F, Campbell C, Tullis E, Brochard L. High-flow nasa oxygen versus noninvasive ventilation in adult patients with cystic fibrosis: a randomized crossover physiological study. Ann Intensive Care. 2018;8:85.

19. Parke R, McGuinness S, Dixon R, Jull A. Open-label, phase II study of routine high-flow nasal oxygen therapy in cardiac surgical patients. Br J Anaesth. 2013;111:925-31.

20. Maggiore SM, Idone FA, Vaschetto R, Festa R, Cataldo A, Antonicelli F, Montini L, De Gaetano A, Navalesi P, Antonelli M. Nasal high-flow versus 
Venturi mask oxygen therapy after extubation. Effects on oxygenation, comfort, and clinical outcome. Am J Respir Crit Care Med. 2014;190:282-8.

21. Corley A, Bull T, Spooner AJ, Barnett AG, Fraser JF. Direct extubation onto high-flow nasal cannulae post-cardiac surgery versus standard treatment in patients with a $\mathrm{BMI}>/=30$ : a randomised controlled trial. Intensive Care Med. 2015:41:887-94.

22. Stephan F, Barrucand B, Petit P, Rezaiguia-Delclaux S, Medard A, Delannoy B, Cosserant B, Flicoteaux G, Imbert A, Pilorge C, Berard L, Bi POPSG. High-Flow Nasal Oxygen vs Noninvasive Positive Airway Pressure in Hypoxemic Patients After Cardiothoracic Surgery: A Randomized Clinical Trial. JAMA. 2015:313:2331-9.

23. Futier E, Paugam-Burtz C, Godet T, Khoy-Ear L, Rozencwajg S, Delay JM, Verzilli D, Dupuis J, Chanques G, Bazin JE, Constantin JM, Pereira B, Jaber S, Os i. Effect of early postextubation high-flow nasal cannula vs conventional oxygen therapy on hypoxaemia in patients after major abdominal surgery: a French multicentre randomised controlled trial (OPERA). Intensive Care Med. 2016:42:1888-98.

24. Hernandez G, Vaquero C, Colinas L, Cuena R, Gonzalez P, Canabal A, Sanchez S, Rodriguez ML, Villasclaras A, Fernandez R. Effect of Postextubation High-Flow Nasal Cannula vs Noninvasive Testo Ventilation on Reintubation and Postextubation Respiratory Failure in High-Risk Patients: A Randomized Clinical Trial. JAMA. 2016a;316:1565-74.

25. Hernandez G, Vaquero C, Gonzalez P, Subira C, Frutos-Vivar F, Rialp G, Laborda C, Colinas L, Cuena R, Fernandez R. Effect of Postextubation HighFlow Nasal Cannula vs Conventional Oxygen Therapy on Reintubation in Low-Risk Patients: A Randomized Clinical Trial. JAMA. 2016b:315:1354-61.

26. Fernandez R, Subira C, Frutos-Vivar F, Rialp G, Laborda C, Masclans JR, Lesmes A, Panadero L, Hernandez G. High-flow nasal cannula to prevent postextubation respiratory failure in high-risk non- hypercapnic patients: a randomized multicenter trial. Ann Intensive Care. 2017;7:47.

27. Yu Y, Qian X, Liu C, Zhu C. Effect of High-Flow Nasal Cannula versus Conventional Oxygen Therapy for Patients with Thoracoscopic Lobectomy after Extubation. Can Respir J. 2017;2017:7894631.

28. Song HZ, Gu JX, Xiu HQ, Cui W, Zhang GS. The value of high-flow nasal cannula oxygen therapy after extubation in patients with acute respiratory failure. Clinics (Sao Paulo). 2017;72:562-7.

29. Rittayamai N, Tscheikuna J, Rujiwit P. High-flow nasal cannula versus conventional oxygen therapy after endotracheal extubation: a randomized crossover physiologic study. Respir Care. 2014;59:485-90. 